\title{
MICRO AND NANOSCALE EDUCATION AT STANFORD UNIVERSITY ${ }^{\S}$
}

\author{
A. Alvin Barlian ${ }^{1}$, Roger T. Howe ${ }^{2}$, Gregory T. A. Kovacs ${ }^{2}$, Beth L. Pruitt ${ }^{1}$ \\ ${ }^{1}$ Department of Mechanical Engineering, ${ }^{2}$ Department of Electrical Engineering \\ Stanford University, Stanford, CA 94305, USA
}

\begin{abstract}
Stanford University is one of the pioneers in the field of micromachining as well as the early devices now classified as microelectromechanical systems (MEMS). The earliest MEMS work at Stanford was a part of the doctoral education of pioneering MEMS researchers and it is captured in several seminal papers and doctoral dissertations. MEMS research at Stanford grew from strong electrical engineering programs in integrated circuits, device physics and fabrication. Over the last two decades, research on micro- and nano-fabricated transducers and devices has become pervasive in all engineering and several science departments at Stanford. The first laboratory course on fabrication technology was offered in 1983, though Stanford's first lecture course surveying micromachined transducers was not offered until 1993, both in the electrical engineering department. Several courses in mechanical and electrical engineering departments followed, that provided further education in analysis and fabrication. More recent courses have focused on applications, such as in bioengineering, or fundamental surface science and bottom-up synthesis methods in materials science. This paper provides a brief history of MEMS at Stanford and reports on our current and planned curriculum.
\end{abstract}

\section{INTRODUCTION}

This paper provides a snapshot of Stanford's role in producing graduates trained in the field, where "the field" is rather inclusive in defining "MEMS" as micromachined, or micro/nanofabricated, and application of these techniques to any transducer. In following these criteria, we acknowledge this may have resulted in the exclusion (or inclusion) of related work. We report primarily on education activities at Stanford related to the training of graduates in "MEMS," including indicators of doctoral dissertations and course enrollments for reference. A large component of MEMS education at Stanford is on the job training through Ph.D. research. An exciting outcome of Stanford's educational activities is the large number of startup companies that grew from academic research at Stanford or from ideas of Stanford graduates. Additional research and startups in the field have also flourished because of work done at Stanford Nanofabrication Facility (SNF) [1] and the synergy of researchers and industry users at this Stanford facility. As one indicator of technology transfer, three of the top 35 revenue generating patents licensed from Stanford as of 2005 were for MEMS devices [2]. SNF was a National Science Foundation (NSF) National Nanofabrication Users Network (NNUN) site from 1994-2004 and has been an NSF National Nanotechnology Infrastructure Network (NNIN) site since 2004. From 2000-2004, the monthly average number of SNF users hovered near 200 with about $25 \%$ from industry [3]. In a survey of lab members in $2005,29.3 \%$ of 140 users responding described their research as MEMS [4].

A recent workshop on MEMS Education in North America identified concerns from industry regarding the quantity of MEMS

$\S$ This paper is dedicated in memory of Prof. James Angell (1924 - Feb 13, 2006). trained graduates at all levels and their preparedness to work in the integrated product and process development environment required for MEMS manufacturing [5]. Academically and industrially, there is a growing cross-disciplinary interest and need for microfabricated tools to interface with nanoscale devices and biological materials. The challenges for educators are in offering a curriculum which: 1) is suited to the needs of students seeking work in MEMS or to apply MEMS to new disciplines, 2) spans the broad interdisciplinary space covered by MEMS device design, 3) addresses the broad cross-disciplinary applications for microdevices, and perhaps most important, 4) creates a technically prepared workforce at the B.S., M.S., and Ph.D. level. Historically, Stanford has performed well in producing MEMS trained graduate students, primarily Ph.D.s through research training. In the past decade, Stanford has enhanced the curriculum with courses suitable for M.S. level students, and in the last few years, with courses accessible to B.S. level students. This paper reviews MEMS education at Stanford University through the present as well as future curriculum plans.

\section{HISTORY OF MEMS AT STANFORD}

Early MEMS research at Stanford was funded by Office of Naval Research (ONR), the National Aeronautics and Space Administration (NASA), and National Institute of Health (NIH), before the term "MEMS" was coined. Stanford Professor of Electrical Engineering James Angell was a pioneer in the field; he is credited with coining the term micromachining in a paper presented in 1978 [6-8]. In the spring of 1966, Angell and his student, Kensall Wise, started work on the first microscale neural probes for surgical applications (funded by ONR); the devices were based on Angell's cutting edge work on integrated circuit (IC) fabrication. This project marked the first microfabrication (silicon micromachining) research at Stanford University. Wise then spent the summer of 1966 learning beam lead technology at Bell Labs, Murray Hill, New Jersey. This technology represents some of the earliest micromachining (for air-isolated integrated circuits) [9]. Wise completed his dissertation on microprobes for biopotential recording in 1969 [10]. The work on microprobes was followed closely by further developments from Angell's group. These included a catheter-tip integrated piezoresistive pressure sensor (Samaun, 1971 [11]), a full-wafer microscale gas chromatography system (Terry, 1975 [12]), an absolute pressure transducer (Nunn, 1977 [13]), and a micromachined accelerometer for biomedical applications (Roylance, 1978 [14]), all sponsored by NASA (NIH also co-funded Nunn's work). As an indicator of impact, at the end of 2005, there were 101 journal papers [15] and 103 U.S. patents [16] that cite Roylance's work $[\mathbf{1 4}, \mathbf{1 7}]$.

In 1969-1970, Vladimir Vaganov, from the Moscow Physics Engineering Institute, visited Angell's group where he "started to work in the field of sensors and micromachining" [18]. Vaganov returned in 1975 and worked on a piezoresistive accelerometer [19]. In 1968-1970, Professor Robert Newcomb of Electrical Engineering attempted to fabricate a surface electromagnetic micromotor [20]. However, materials incompatibility with the 
Stanford Microelectronics Lab's research focus on electronic devices was a major issue. After leaving Stanford for the University of Maryland, Newcomb published a proposal for resonant silicon cantilever beam high-Q MEMS filter, which acknowledges discussions with Vaganov [21]. In 1980, Professor James Meindl reported on a micromachined capacitive pressure sensor [22].

Since 1969, 135 MEMS related doctoral dissertations have been completed and many more are in progress. Figure 1 shows the number of doctoral dissertations related to MEMS from Stanford University since 1969. An advanced microfabrication projects course, EE357, was offered from 1983-1998 and taught by Professors Butrus Khuri-Yakub and David Bloom, both in the electrical engineering department [23]. The first lecture course surveying micromachined transducers was first offered in 1993 by Professor Gregory Kovacs in the electrical engineering department [24]. While the first research and courses were in the electrical engineering department, there has been an increase in the number of faculty with MEMS-related research in other departments. Figure 1 also reflects this demographic shift in MEMS doctoral graduates.

\section{CURRICULUM AT STANFORD}

There has been no school-wide coordination of the micro and nanoscale courses at Stanford. Rather, courses have "selfassembled" in departments to meet the needs of students and researchers at Stanford. MEMS, microscale, and nanoscale courses at Stanford are primarily offered as graduate-level engineering courses and thus are taken most by graduate students ( $96 \%)$. Enrollment data categorized by declared major for the last 5 years show recent trends in student interest in these courses. Figure 2 provides summary statistics for course enrollment by major. Enrollment numbers reflect the number of students registered for the course. However, some courses have limited enrollments and several auditors in attendance. From anecdotal evidence, instructors believe there may be extensive uncounted use of some course materials available online. This is more difficult to track and report, but is in the spirit of the MEMS Education Workshop suggestion of creating archives of shared course materials.

Stanford is on a quarter system; most courses run 10 weeks (plus finals) in the academic year (Autumn, Winter, and Spring), with few in Summer ( 8 weeks + finals). MEMS related courses are offered in the bioengineering, electrical, material science, and mechanical engineering departments. Courses are loosely grouped below into those focused on design and fabrication of broad classes of devices, and those focused on more specialized device analysis. Descriptions of course content and pedagogy follow and summary syllabi for the courses are appended in Table 1. The topics covered by particular courses in the curriculum are condensed in Table 2 .

\section{Microscale and Nanoscale Design and Fabrication Courses}

The following courses address how devices, products, or associated materials are made, i.e., the art, engineering, and technology of product and process at the nano- and micro- scale. Instructors are listed after the course title.

EE312 Micromachined Sensors and Actuators was the first MEMS-related lecture class at Stanford. Professor Gregory Kovacs developed this course in 1993 and taught it from 1993 to 2003. His lecture notes evolved into one of the earliest textbooks on micromachined transducers [25]. Professor Roger Howe recently taught it in Winter 2006 after joining Stanford in 2005. EE312 reviews microfabrication processes, introduces relative merits of different technologies, and focuses on various transduction mechanisms at the microscale through lectures/ homework/term-paper format. Categories of sensors and actuators include biological, chemical, mechanical, optical, and thermal.

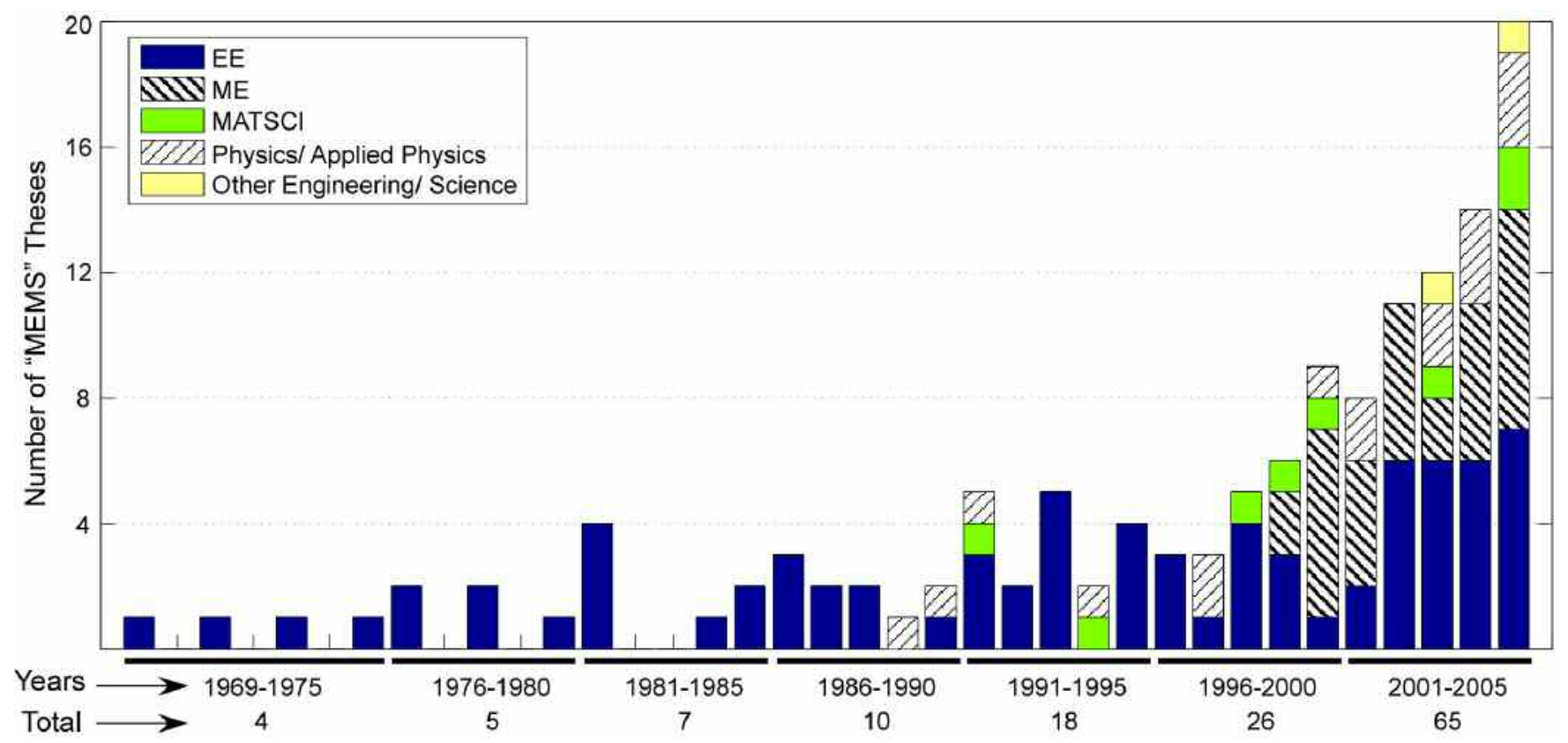

Figure 1. Estimated count of MEMS theses from 1969 to 2005. The imprinting year of doctoral dissertation at Stanford is reported here, though demonstrations of these devices and other publications were completed earlier. The data were compiled from a search of the library archives. Dissertations were indexed 1) by advisor, for graduates advised by professors involved in MEMS research, and 2) by title for common terminology such as MEMS, micro, micromachined, microfabricated, etc. Titles and degree granting department were verified manually (abstracts were read if the title was not clear). 


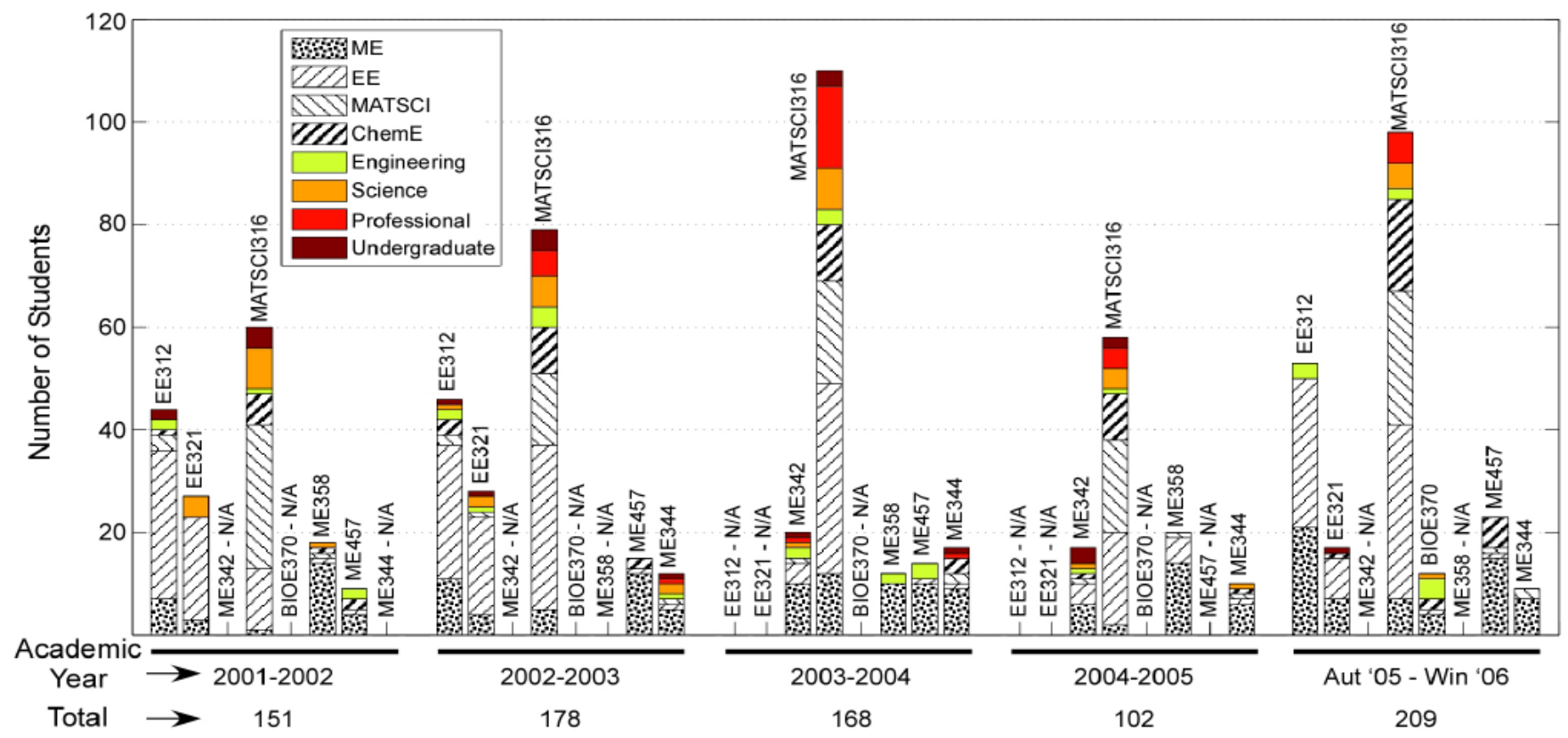

Figure 2. Enrollment from 2001-2002 to Aut'05-Win'06 academic year for MEMS, microscale, and nanoscale courses [26], which are detailed in Table 1 and 2. In the legends, Engineering includes: BioE, Aero, Civil and Environmental, Management Science \& Engineering, and general engineering. Science includes: Applied Physics, Physics, Chemistry, Computer Science, and Geology. Professional includes: Medicine, Business, Law, and Non-degree.

EE321 MEMS Design (Solgaard) reviews microfabrication processes and exposes students to MEMS design rules through lectures/homework/final-project format. The emphasis is on physical understanding and elementary modeling of MEMS devices. During the course, students complete a MEMS design project including layout, evaluation strategy, and modeling. Case studies of successful MEMS devices are presented throughout the quarter.

ME342A MEMS Laboratory I (Pruitt) is a two-quarter class for all technical majors, including undergraduates. It emphasizes theory and practice of MEMS device design and fabrication. Students are introduced to fabrication facilities and basic microfabrication processes through biweekly lectures and weekly laboratories. Laboratories include photolithography, wet and dry etching, oxidation and diffusion. Transduction mechanisms and fabrication techniques are introduced. Students process wafers using pre-designed masks for piezoresistive force sensors. They also package, test and calibrate the devices. Students qualify as
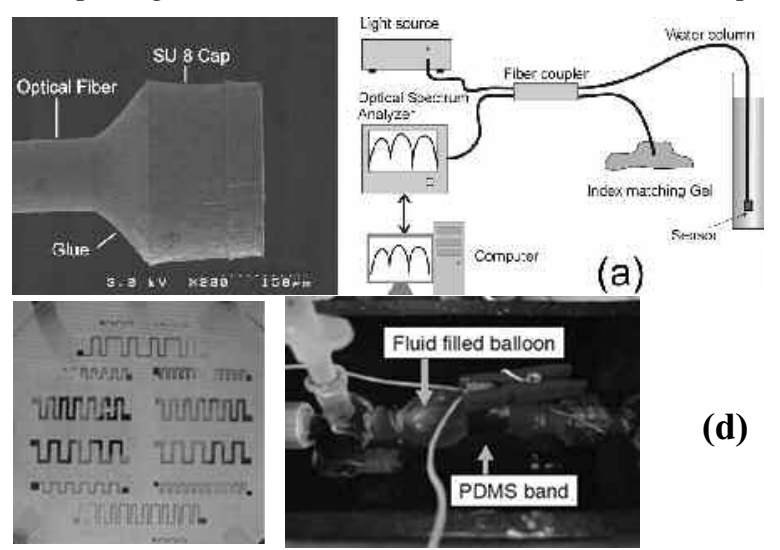

(d) independent users of SNF. Students work in 3-4 person teams to design solutions for predefined challenges. These projects originate from internal research collaborations within Stanford or from industry sponsors (past affiliates include Intel, Agilent, Careside, and Fultec).

ME342B MEMS Laboratory II (Pruitt) is offered in the summer quarter. In part A, student teams collaborated with project affiliates to invent, develop, and design microfabricated solutions. In part $\mathrm{B}$, functional prototypes are fabricated and tested using at least one processing approach but several design layouts on one set of masks per team. Students use fabrication facilities independently for the projects with minimal staff burden. Several ME342 projects continue beyond the course as M.S. or Ph.D. projects; those resulting in conference publications are shown in Figure 3. Enrollment is limited by laboratory constraints to 20 students in both part A and B.
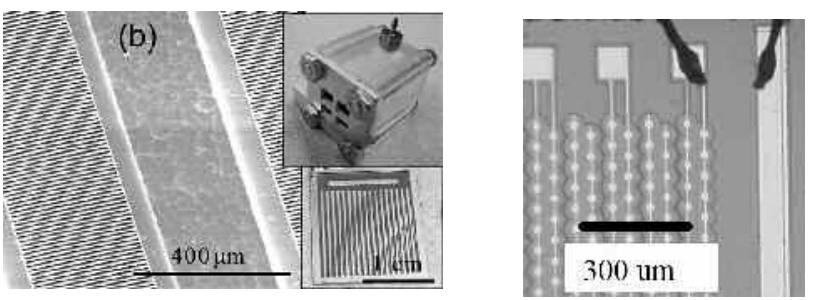

(c)

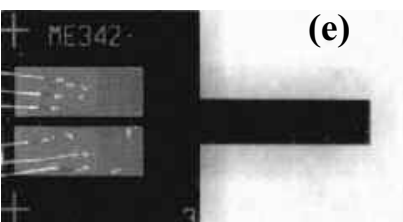

Figure 3. Some ME342 projects that resulted in conference publications: (a) Miniature SU-8 interferometric blood pressure sensor [27]; (b) Electroosmotic pump integrated with miniaturized fuel cell [28]; (c) Biocompatible coatings for MEMS ultrasonic sensors [29]; (d) 100\%-Radial strain gauge for monitoring aneurism formation in rat aorta [30]; (e) ME342 piezoresistive force sensing cantilevers and noise studies for implanted piezoresistors [31]. 
MATSCI160 Nanomaterials Laboratory (Melosh) is designed for undergraduate students interested in nanoscience and nanotechnology and will be offered in Spring 2005/2006 for the first time. It explores synthesis and characterization techniques in nanotechnology. The labs cover several different approaches to creating nanomaterials, including syntheses of silicon nanowires, gold nanoparticles, nanorods, photonic band-gap crystals and nanopatterning surfaces using soft lithography. Students are introduced to state-of-the-art characterization equipment to analyze these samples, such as Scanning Electron Microscopy (SEM), Transmission Electron Microscopy (TEM), and Atomic Force Microscopy (AFM).

MATSCI316 Nanoscale Science, Engineering, and Technology (McGehee) introduces students to nanofabrication techniques, such as self-assembly of amphiphilic molecules, block copolymers, organic-inorganic mesostructures, colloidal crystals, organic monolayers, proteins, DNA, and abalone shells. In addition, students are introduced to tools used for nanocharacterization of materials, nanoelectronics, nanotubes, nanowires, nanocrystals, and nanotechnology-based renewable energy. It has attracted more than 300 students from various engineering/science departments, as well as from Law, Medicine, and Business since 2002. MATSCI316 is based on lectures/homework/final-project format and offered online through Stanford Center for Professional Development (SCPD) since 2001.

BIOE370 Microfluidic Device Laboratory (Quake and Melin) covers design, fabrication, and testing of microfluidic devices for biological applications. The laboratory sessions include soft lithography (mostly PDMS) to create micromechanical valves and pumps. The emphasis of this course is on device design, fabrication, and testing of basic microfluidic chips. In the first half of the course, students are introduced to microfluidics and fabrication processes as they go through fabrication and testing of a pre-designed microfluidic chip. In the second half, students are more independent and are assigned to design their own microfluidic chips in small groups. They fabricate, and test these chips with the test apparatus provided. This course was first offered in Winter 2006 quarter and limited to 12 students. A condensed version of this course ( 3 days) will also be offered in July 2006.

\section{Microscale and Nanoscale Device Analysis Courses}

In addition to MEMS design and fabrication courses, Stanford offers several advanced topic microscale and nanoscale device analysis courses.

ME358 Heat Transfer in Microdevices (Goodson) introduces novel theoretical and experimental aspects of heat transfer in microdevices. Students are introduced to thermal design of electronic circuits, sensors, and actuators in microscale. The course also covers thermal property measurements for microdevices with emphasis on $\mathrm{Si}$ and $\mathrm{GaAs}$ semiconductor devices and thin films. ME358 is taught in lectures/midterm/final-project format. Final projects are based on student research interests.

ME457 Fluid Flow in Microdevices (Santiago) is an introductory course to physicochemical forces associated with fluid flow in microscale devices and emphasizes bioanalytical microfluidics system applications. The course covers creeping flow, electric double layers, and electrochemical transport. Emphasis is on bioanalytical applications in which electrophoresis, electro-osmosis, and diffusion are important. ME457 is taught in lectures/midterm/final-exam/final-project format. Final projects are based on individual student research interests.
ME344A\&B Computational Nanotechnology and Nanomaterials Modeling (Cho) is a two-quarter class. In the first quarter, it introduces students to atomistic simulations as computational tools to design nano-scale materials and devices. In the second quarter, it introduces students to various techniques for atomistic simulations, such as finite difference algorithms, molecular dynamics, and Monte Carlo simulations. It offers students hands-on experience in computational design of nanomaterials and the fundamentals of simulations.

In addition to the courses mentioned above, there are other courses offered by various departments in the School of Engineering, which emphasize on characterization, modeling, and analysis of micro and nanoscale phenomena. These courses are not specific to engineering devices but provide the background necessary for more in depth study of physical phenomena important to micro/nano interfaces and design. Some examples include Elasticity in Microscopic Structures (ME), Nanophotonics (EE), Nanocharacterization of Materials, Microstructures and Mechanical Properties (MatSci), Probing the Nanoscale (AP), etc.

Faculty have also added microscale/nanoscale/MEMS as examples or modules to other courses they teach in the EE and ME undergraduate curriculum. MEMS examples are an effective means of engaging students in thinking about interdisciplinary and integrative solutions. In addition, the bioengineering department (established in 2002) also integrates lectures and materials related to MEMS and microfluidics in its graduate core curriculum through BIOE200A, B, and C (developed by Kovacs, Ku, and Sorger).

\section{CONCLUSIONS}

Stanford University has helped lay the foundation for MEMS as a field. A large component of MEMS education at Stanford is on the job training through Ph.D. research. MEMS has grown out from the electrical engineering department and has become interdisciplinary. Formal courses in various engineering departments have developed because of faculty interest in microscale/nanoscale/MEMS-related research. As the field has matured, MEMS training is becoming part of the core toolbox for many engineering students.

\section{FUTURE PLAN}

A portion of the curriculum will be revised in 2006-07 to reflect the interdepartmental nature of micro and nanoscale engineering and to provide more "MEMS trained" B.S. and M.S. graduates. Professors Howe, Pruitt, and Solgaard will replace EE321 and ME342AB with a three-quarter engineering sequence with no prerequisites and no departmental designation. It is expected that a large percentage of Stanford's graduating M.S. students will take at least the first of these courses. The courses will be available to senior undergraduates and industry through SCPD, partially addressing concerns raised by MEMS industry participants of the 2005 MEMS Education Workshop and Survey [5].

\section{ACKNOWLEDGEMENTS}

The authors would like to thank Joe Mallon, Prof. Ken Wise, Dr. Kurt Peterson, Dr. Phil Barth, and Dawn Levy for helpful discussion in preparation of this manuscript. We thank the faculty for providing information on their courses: Professors Kyeongjae Cho, Kenneth Goodson, Thomas Kenny, Butrus Khuri-Yakub, 
Michael McGehee, Nicholas Melosh, Stephen Quake, Juan Santiago, Olav Solgaard, and Dr. Jessica Melin. We are extremely grateful for Indrani Gardella's assistance with compilation and verification of class enrollment data from the Office of the University Registrar. Special thanks to Matt Beasley, Amy Lee, and Betty Zhao for library research. Fabrication work was performed in part at the SNF (a member of the NNIN) which is supported by the NSF under Grant ECS-9731293, its lab members, and the industrial members of the Stanford Center for Integrated Systems. The authors would like to thank the SNF's staff for support in the lab. Travel support was generously provided by the Transducers Research Foundation.

Table 1. Syllabi by week of microscale and MEMS courses at Stanford (number of prerequisites is in parenthesis)

\begin{tabular}{|c|c|c|c|c|c|}
\hline Week & EE312 (1) & EE321 (2) & ME342A (0) & BIOE370 (0) & MATSCI160 (0) \\
\hline 1 & Intro, MEMS, Nano & Introduction, Fabrication & Overview, Fabrication & $\begin{array}{l}\text { Introduction, Overview of } \\
\text { Fabrication Processes }\end{array}$ & Gold Nanorod Synthesis \\
\hline 2 & Scaling, Micromachining & Fabrication, Actuators & Implants, Transduction & $\begin{array}{l}\text { Making Molds for Device } \\
\text { Example }\end{array}$ & $\begin{array}{c}\text { Transmission Electron } \\
\text { Microscopy } \\
\text { Characterization }\end{array}$ \\
\hline 3 & Micromachining & Actuators & Litho, Micromachining & $\begin{array}{c}\text { Making Chips for Device } \\
\text { Example }\end{array}$ & Silicon Nanowire Synthesis \\
\hline 4 & $\begin{array}{c}\text { Micromachining, } \\
\text { Packaging, } \\
\text { Microelectromechanics } \\
\end{array}$ & Accelerometers & Etching/Brainstorming & Testing of Rotary Pump & $\begin{array}{c}\text { Scanning Electron } \\
\text { Microscopy and Atomic } \\
\text { Force Microscopy } \\
\end{array}$ \\
\hline 5 & Microelectromechanics & Dynamics & MEMS Reliability & Group Project - Design & Photonic Crystals \\
\hline 6 & $\begin{array}{l}\text { Microelectromechanics, } \\
\text { Microfluidics }\end{array}$ & Stress & Mechanics & Group Project - Molds & $\begin{array}{l}\text { Self-assembly and } \\
\text { Colloidal Forces }\end{array}$ \\
\hline 7 & $\begin{array}{c}\text { Chemical, Biological } \\
\text { Transducers }\end{array}$ & Structures & Microfluidics & Group Project - Chips & Soft Lithography \\
\hline 8 & $\begin{array}{l}\text { Magnetic Transducers, } \\
\text { Optical MEMS }\end{array}$ & Virtual work & $\begin{array}{l}\text { Packaging, Signal } \\
\text { Conditioning }\end{array}$ & $\begin{array}{l}\text { Testing of Group Device in } \\
\text { Optical Test Setup }\end{array}$ & Contact Angles, Patterning \\
\hline 9 & $\begin{array}{c}\text { RF MEMS, Integrated } \\
\text { MEMS }\end{array}$ & Fluids & Soft Litho/Biomedical & $\begin{array}{l}\text { Testing of Group Device in } \\
\text { Optical Test Setup }\end{array}$ & Surface Functionalization \\
\hline 10 & Final Project Presentations & Conclusions & Projects & Group Presentation & Presentations \\
\hline
\end{tabular}

\begin{tabular}{|c|c|c|c|c|}
\hline Week & MATSCI316 (0) & $\operatorname{ME} 358\left(0^{\dagger}\right)$ & $\operatorname{ME} 457\left(0^{\dagger}\right)$ & ME344A (1) \\
\hline 1 & Introduction & Introduction, Thermal Modeling & Introduction, Basic Principles & Introduction \\
\hline 2 & Self Assembly & Conduction Modeling & Transport Equation, Electrostatics & Atomic Structures of Solids \\
\hline 3 & $\begin{array}{c}\text { Colloidal Crystals, Organic } \\
\text { Monolayers }\end{array}$ & Convection Modeling & $\begin{array}{l}\text { Convective Diffusion, } \\
\text { Taylor Dispersion }\end{array}$ & Inter-atomic Interactions \\
\hline 4 & $\begin{array}{c}\text { Biopolymers, Abalone Shells, } \\
\text { Biomimetics }\end{array}$ & Thermometry & $\begin{array}{c}\text { Uncharged Macromolecules, } \\
\text { Brownian Motion }\end{array}$ & $\begin{array}{c}\text { Atomic Structure Optimization of } \\
\text { Nanomaterials }\end{array}$ \\
\hline 5 & Scanning Probe Techniques & $\begin{array}{l}\text { Thermal Conductivity } \\
\text { Measurements }\end{array}$ & $\begin{array}{c}\text { Introduction to Electrolytic } \\
\text { Solutions }\end{array}$ & Molecular Dynamics \\
\hline 6 & $\begin{array}{l}\text { Synthesis of Nanocrystals, } \\
\text { Nanowires, and Nanotubes }\end{array}$ & Radiation, Optical Devices & Charged Double Layer & Molecular Dynamics \\
\hline 7 & Nanopatterning, Nanoelectronics & Heat Transfer in VLSI Systems & Electroosmosis & Monte Carlo Simulations \\
\hline 8 & $\begin{array}{c}\text { Organic Electronics, Molecular } \\
\text { Electronics }\end{array}$ & Micro Sensors \& Actuators & $\begin{array}{l}\text { Charged Macromolecules and } \\
\text { Particles, Electrophoresis }\end{array}$ & Monte Carlo Simulations \\
\hline 9 & Nanowire and Nanotube Devices & Microchannel Convection & Intermediate Topics & Applications to Nanomaterials \\
\hline 10 & $\begin{array}{c}\text { Solar Cells, Hydrogen Storage, } \\
\text { Fuel Cells }\end{array}$ & Final Project Presentations & Final Project Discussions & Applications to Nanomaterials \\
\hline
\end{tabular}

\footnotetext{
$\dagger$ with consent of instructor
} 
Table 2. Topical areas of microscale and MEMS courses at Stanford

\begin{tabular}{|c|c|c|c|c|c|c|c|c|c|}
\hline TOPICS & EE312 & EE321 & ME342 & ME358 & ME457 & $\begin{array}{c}\text { BIOE } \\
370\end{array}$ & $\begin{array}{l}\text { MATSCI } \\
316\end{array}$ & $\begin{array}{l}\text { MATSCI } \\
160\end{array}$ & ME344 \\
\hline Physics & & & & $\sqrt{ }$ & $\sqrt{ }$ & & & & $\sqrt{ }$ \\
\hline Mechanics & $\sqrt{ }$ & $\sqrt{ }$ & $\sqrt{ }$ & $\sqrt{ }$ & $\sqrt{ }$ & & & & $\sqrt{ }$ \\
\hline Materials & $\sqrt{ }$ & $\sqrt{ }$ & $\sqrt{ }$ & $\sqrt{ }$ & & & $\sqrt{ }$ & $\sqrt{ }$ & $\sqrt{ }$ \\
\hline Electrical & $\sqrt{ }$ & $\sqrt{ }$ & $\sqrt{ }$ & $\sqrt{ }$ & $\sqrt{ }$ & & $\sqrt{ }$ & & $\sqrt{ }$ \\
\hline Biology & $\sqrt{ }$ & $\sqrt{ }$ & $\sqrt{ }$ & & $\sqrt{ }$ & $\sqrt{ }$ & $\sqrt{ }$ & & \\
\hline $\begin{array}{l}\text { Surface Chemistry/ } \\
\text { Synthesis }\end{array}$ & & & & & & & $\sqrt{ }$ & $\sqrt{ }$ & \\
\hline Chemistry & $\sqrt{ }$ & $\sqrt{ }$ & $\sqrt{ }$ & & & & $\sqrt{ }$ & $\sqrt{ }$ & \\
\hline Device Design & & $\sqrt{ }$ & $\sqrt{ }$ & & & $\sqrt{ }$ & & & \\
\hline Experiment Design & & & $\sqrt{ }$ & & & $\sqrt{ }$ & & & \\
\hline Analysis & $\sqrt{ }$ & $\sqrt{ }$ & $\sqrt{ }$ & $\sqrt{ }$ & $\sqrt{ }$ & & & $\sqrt{ }$ & $\sqrt{ }$ \\
\hline Testing & & & $\sqrt{ }$ & & & $\sqrt{ }$ & & $\sqrt{ }$ & \\
\hline Fabrication lecture & $\sqrt{ }$ & $\sqrt{ }$ & $\sqrt{ }$ & & & $\sqrt{ }$ & $\sqrt{ }$ & $\sqrt{ }$ & \\
\hline Fabrication lab & & & $\sqrt{ }$ & & & $\sqrt{ }$ & & $\sqrt{ }$ & \\
\hline
\end{tabular}

\section{REFERENCES}

[1] Stanford Nanofabrication Facility, http://snf.stanford.edu

[2] "Stanford Office of Technology Licensing Annual Report 2004-2005."

[3] Personal communication, email, P. Rissman to B. Pruitt, March 27, 2006

[4] Stanford Nanofabrication Facility Lab Members Survey, http://snf.stanford.edu/Labmembers/SurveySummary.html

[5] Report of the MEMS Education Workshop 2005, Miami, FL, http://memsed.stanford.edu/

[6] J. B. Angell, "Micromachined Silicon Transducers for Measuring Force, Pressure, and Motion," 4th European SolidState Circuits Conference, Amsterdam, 1978.

[7] L. Rafkin, "The Founder," in Forbes, 2001.

[8] D. Levy, "James Angell, electrical engineer and former carillonneur, dies," in Stanford Report. Stanford, CA, 2006.

[9] Personal communication, email, K. Wise to A. A. Barlian, Friday, March 17, 2006

[10] K. D. Wise, "A Multielectrode Microprobe for Biopotential Recording," Ph.D. thesis in Electrical Engineering Department, Stanford University, 118, 1969

[11] Samaun, "An Integrated Circuit Piezoresistive Pressure Sensor for Biomedical Instrumentation," Ph.D. thesis in Electrical Engineering Department, Stanford University, 72, 1971

[12] S. C. Terry, "A Gas Chromatography System Fabricated on a Silicon Wafer Using Integrated Circuit Technology," Ph.D. thesis in Electrical Engineering Department, Stanford University, 146, 1975

[13] T. A. Nunn, "A Silicon Absolute Pressure Transducer for Biomedical Applications," Ph.D. thesis in Electrical Engineering Department, Stanford University, 106, 1977

[14] L. M. Roylance, "A Miniature Integrated Circuit Accelerometer for Biomedical Applications," Ph.D. thesis in Electrical Engineering Department, Stanford University, 207, 1978

[15] SciSearch ${ }^{\circledR}$ Plus at LANL, http://search.lanl.gov/

[16] L. D. Harper, et al., "Fair Broker Assessment of NASA Contribution to MEMS Technology," NASA Ames Research Center 2003.

[17] L. Roylance and J. Angell, "Batch-Fabricated Silicon Accelerometer," IEEE Transactions on Electron Devices, vol. 26, pp. 1911-1917, 1979.
[18] V. Vaganov, "Packaging and Testing Issues in MEMS Commercialization," SEMI Technical Paper, 1998.

[19] Personal communication, letter, V. Vaganov to G. Kovacs, February 23, 2000

[20] K. Dutta, et al., "Integrated Micromotor Concepts," International Conference on Microelectronic Circuits and System Theory, Sydney, Australia, 1970.

[21] M. F. Hribsek and R. W. Newcomb, "High-Q Selective Filters Using Mechanical Resonance of Silicon Beams," IEEE Transactions on Circuits and Systems, vol. CAS-25, pp. 215222, 1978.

[22] C. Sander, et al., "A Monolithic Capacitive Pressure Sensor with Pulse-Period Output," IEEE Transactions on Electron Devices, vol. 27, pp. 927-930, 1980.

[23] Personal communication, email, P. Khuri-Yakub to A. Barlian, March 18, 2006

[24] Personal communication, email, G. T. A. Kovacs to A. A. Barlian, March 17, 2006

[25] G. T. A. Kovacs, Micromachined Transducers Sourcebook, 1st ed: McGraw-Hill Science/Engineering/Math, 1998.

[26] The Office of the University Registrar, Stanford University

[27] R. Melamud, et al., "Development of An SU-8 Fabry-Perot Blood Pressure Sensor," 18th IEEE International Conference on Micro Electro Mechanical Systems, Miami, Florida, USA, 2005.

[28] C. R. Buie, et al., "A Microfabricated Direct Methanol Fuel Cell with Integrated Electroosmotic Pump," 19th IEEE International Conference on Micro Electro Mechanical Systems, Istanbul, Turkey, 2006.

[29] M. A. Beasley, et al., "A Biocompatible Coating for CMUT," Materials Research Society Spring Meeting, San Francisco, CA, USA, 2006.

[30] E. T. Hantsoo, et al., "Characterization of Modified Polymers for High Elongation Strain Sensing," Materials Research Society Spring Meeting, San Francisco, CA, USA, 2005.

[31] A. A. Davenport, et al., "Noise Studies in Implanted Piezoresistors," International Mechanical Engineering Congress and Exposition, Orlando, Florida, USA, 2005. 